\title{
Correction to: The RBF partition of unity method for solving the Klein-Gordon equation
}

\author{
Mohammadreza Ahmadi Darani ${ }^{1}$
}

Published online: 13 November 2020

๑) Springer-Verlag London Ltd., part of Springer Nature 2020

\section{Correction to: Engineering with Computers https://doi.org/10.1007/s00366-020-01171-z}

The article, "The RBF partition of unity method for solving the Klein-Gordon equation", written by Mohammadreza Ahmadi Darani1 was originally published electronically on the publisher's internet portal (currently SpringerLink) on 19 September 2020 with open access. With the author(s)' decision to step back from Open Choice, the copyright of the article changed on 10 December 2020 to $\odot$ Springer-Verlag GmbH Germany, part of Springer Nature 2020 and the article is forthwith distributed under the terms of copyright.

The original article was corrected.

Publisher's Note Springer Nature remains neutral with regard to jurisdictional claims in published maps and institutional affiliations.

The original article can be found online at https://doi.org/10.1007/ s00366-020-01171-z.

Mohammadreza Ahmadi Darani

ahmadi.darani@sku.ac.ir

1 Department of Applied Mathematics Faculty

of Mathematical Sciences, Shahrekord University, P. O.

Box 115, Shahrekord, Iran 